DOI 10.30612/re-ufgd.v4i8.8118

\title{
O ALUNO SURDO - DA EDUCAÇÃO AO MERCADO DE TRABALHO NA PROMESSA LEGAL E NA REALIDADE DE PONTA PORÃ
}

The Deaf Student - From Education to the Job Market in the Legal Promise and Reality of Ponta

Porã

Jakellinny Gonçalves de Souza Rizzo ${ }^{1}$

Karla Alexandra Benites Florenciano ${ }^{2}$

Recebido em 15/10/2017

Aceito em 15/12/2017

Resumo: O presente objetivou analisar à maneira que a escola tem contribuído para a inserção do aluno surdo no mercado de trabalho. Pesquisa bibliográfica e empírica. Apresenta-se uma visão histórica da educação dos surdos, oportunizando conhecer as principais correntes metodológicas que nortearam a educação dos mesmos em diversos períodos históricos, bem como o papel de diversos componentes da comunidade escolar em relação à inclusão do aluno surdo na sociedade e no mercado de trabalho. A pesquisa de campo realizou-se em uma escola pública de rede estadual, sob a forma de entrevistas realizadas com os alunos surdos. Verificou-se que na prática essa escola tem contribuído pouco para a inserção dos alunos surdos no mercado de trabalho, pois estes, muitas vezes, não conseguem ter uma plena comunicação nem dentro da escola, muito menos fora dela.

Palavras-chaves: Escola. Libras. Surdez. Inclusão.

Abstract: The present study aimed to analyze the way in which the school has contributed to the insertion of the deaf student in the labor market. Bibliographical and empirical research. It presents a historical view of the education of the deaf, making it possible to know the main methodological currents that guided their education in different historical periods, as well as the role of several components of the school community in relation to the inclusion of the deaf student in society and in the market of work. Field research was carried out in a public school of the state network, in the form of interviews with the deaf students. It has been found that in practice this school has contributed little to the insertion of deaf students in the labor market, since they often cannot have full communication in school, much less outside it.

Key words: School. Libras. Deafness. Inclusion.

\section{Introdução}

\footnotetext{
${ }^{1}$ Mestranda em Educação - UFGD - E-mail: jake.librasufgd@gmail.com

${ }^{2}$ Graduada em Pedagogia, pós-graduada em Psicopedagogia, acadêmica do curso de Letras/Libras - UFGD.

Professora do curso de Pedagogia - UFMS/CPPP - E-mail: karlinhaben@gmail.com
}

A história promove a reflexão e o entendimento dos fatos atuais revelando que o presente não está descolado do passado; por 
isso no primeiro momento será feita uma síntese da história da Educação dos Surdos, história que passou por diversas idas e vindas, proibições e permissões. Para esclarecer melhor serão citados três tipos de metodologias usadas na educação de Surdos.

Segundo Honora e Frizanco (2009) são eles: o Oralismo que tem como objetivo a produção de uma língua oral e vê a língua de sinais como um problema para o desenvolvimento da fala, o segundo tipo de metodologia objetiva a comunicação total; tendência essa que percebe toda comunicação como válida, seja ela: fala; leitura orofacial; treinamento auditivo; expressão facial; corporal; mímica; leitura e escrita e sinais. $\mathrm{O}$ terceiro e mais atual dos métodos é o bilinguismo, que nasceu na Suécia, e teve como princípio metodológico fundamental a ótica em relação à língua de sinais, isto é, propunha-se que ela fosse vista como a primeira língua (língua materna) da comunidade surda. Nesse caso, "a fala é vista como uma possibilidade e não como uma obrigação" (HONORA e FRIZANCO, 2009, p.15).

Através dessa afirmação é possível perceber a forte influência que a língua de sinais tem na contemporânea tendência metodológica para a educação dos surdos; porém para tal conquista inúmeras pessoas com surdez em diversos períodos históricos lutaram pelo reconhecimento de sua língua e de sua forma de comunicação, por isso o bilinguismo para os surdos, nada mais é do que o fruto de uma luta que durou séculos.

A educação dos surdos na antiguidade variava de acordo com a concepção sobre eles. $\mathrm{Na}$ Grécia, por exemplo, valorizava-se muito uma educação que visava à formação cortês do nobre, ou seja, formar o "guerreiro belo e bom", um homem que soubesse proferir palavras e realizar ações, segundo Aranha (1996), na educação espartana isso é bem claro, pois era recomendado que fossem abandonadas as crianças com deficiência ou frágeis demais. Os gregos também valorizavam o estudo da música, canto e dança coletiva.

Os romanos por sua vez, segundo a autora já citada também valorizavam a arte de bem escrever e bem falar; nesse período aristocrático o interesse maior era nas atividades intelectuais, excluindo assim o trabalho manual. Tanto para os gregos como para os romanos, o surdo não era considerado humano, pois a fala era resultado do pensamento, logo quem não pensava não era humano. Até o século XII, os surdos eram privados de tudo: de conviver na sociedade, da escolarização e até mesmo de se casarem. “Aristóteles afirmou que considerava o ouvido o órgão mais importante para a educação, o que contribuiu para que o surdo 
fosse visto como incapacitado para receber instrução naquela época" (HONORA e FRIZANCO, 2009, p.19).

Já na Idade Média a Igreja Católica exercia uma forte influência sobre a sociedade, por isso ela foi fundamental para a discriminação dos surdos, pois a mesma acreditava que o homem é a imagem e semelhança de Deus, sendo assim quem não se encaixava nesse padrão não era considerado humano, principalmente; os surdos, pois eles não se confessavam e suas almas eram consideradas mortais já que os mesmos não podiam falar os sacramentos. No entanto, a Igreja Católica se preocupava com os surdos que pertenciam as famílias abastadas, pois se eles possuíssem uma língua própria e se fossem instruídos poderiam participar dos ritos, dizer os sacramentos, e também continuariam em suas posições. Prosseguiriam ajudando a Santa Madre Igreja. Foi então que surgiu a primeira tentativa de educar os surdos, através de alguns monges que tinham feito voto de silêncio para não passarem adiante os conhecimentos adquiridos nos livros sagrados. Estes para não ficarem totalmente incomunicáveis desenvolveram uma linguagem gestual que passaram a ensinar aos surdos, e dessa forma os monges tornaram-se primeiros preceptores dos surdos.
O Brasil começou com a educação de surdos a partir do Segundo Império, pois veio, para o país um ex-aluno surdo do Instituto de Paris, dessa forma originou-se a LIBRAS, com muita influência da Língua de Sinais Francesa. Com o apoio de D.Pedro II, foi fundado em 1857, o primeiro Instituto de surdos-mudos, pois o mesmo tinha grande interesse na educação dos surdos, por ter um neto surdo, filho da princesa Isabel que era casada com o Conde D'eu (HONORA e FRIZANCO, 2009, p.27).

Inicialmente esse Instituto usou a Língua de Sinais, mas assim como no resto do mundo, também teve que adotar o método do Oralismo, em 1911. Esse Instituto promovia várias oficinas de sapataria, encadernação e pautação de cadernos. Em 1930, o Instituto esteve sob a direção do Dr. Armando Paiva Lacerda, que como gestor também acreditava que o método oral era a melhor maneira de educar o surdo; ele considerava que os educandos mais inteligentes eram aqueles que tinham capacidade de oralizar e por isso separava por nível, dessa forma os menos capacitados ficavam em salas diferentes dos demais.

Em 1951, o Instituto já tinha quase 100 anos, quando pela primeira vez teve em sua gestão um profissional da educação que foi a prof. $^{a}$ Ana Rimoli de Faria Dória, a que implantou o curso de formação de professores 
para surdos, que tinha duração de três anos, sendo o método adotado, aquele que era todo voltado para o Oralismo.

Na década de 1970, mais precisamente em 1973, o Capital Brasileiro teve um aumento nunca visto antes.

\begin{abstract}
Nesse período, o governo interveio com intensidade na economia nacional, indexando salários, expandindo o crédito ao consumidor, sobretudo o destinado à classe média (que comprou, automóveis, eletrodomésticos, etc.) estimulando a poupança interna, concedendo isenção fiscal a alguns setores da agricultura e da indústria (sobretudo para a indústria automobilística). A atuação do Estado nas obras de infraestrutura (telecomunicação, estradas, energia, etc.) também foi significativa e modernizadora, geralmente realizada com capital externo. Esse processo ficou conhecido como modernização conservadora. (MORAES, 2005, p.421)
\end{abstract}

Esse período de modernização consequentemente teve reflexo no cotidiano das pessoas com surdez, pois muitos puderam ter acesso ao televisor, cujas imagens os auxiliava na aquisição de informações. Porém, a grande inovação brasileira na educação para os surdos ocorreu com a visita da educadora de surdos da Universidade Gallaudet, Ivete Vasconcelos, que juntamente com as pesquisas de Lucinda Brito, passou a difundir o bilinguismo.

Outros institutos também tiveram relevância na história da educação dos surdos no Brasil, como por exemplo: o Instituto Santa
Teresinha que atualmente é de natureza particular e fica em São Paulo, atendendo apenas ao Ensino Fundamental. Outra Instituição de suma importância é a IESP Instituto Educacional São Paulo, que foi fundada em 1954, atualmente pertence a PUC/SP e é referência nacional para pesquisas e estudos na área da deficiência auditiva.

A Inclusão de alunos Surdos em classes regulares requer da educação muito mais do que professores intérpretes ou tradutores, ela necessita de professores habilitados que saibam acolher e comunicar-se com esses alunos.

Esse é um dos motivos pelo qual a grade curricular dos cursos de licenciatura deverá sofrer ajustes, para que os futuros docentes aprendam práticas de ensino adequado às diferenças e uma das mudanças já efetuada é a inclusão das LIBRAS, como disciplina curricular, no curso normal de nível médio, no Curso Normal Superior, no curso de Pedagogia e também nos cursos de Fonoaudiologia e demais cursos de formação de professores e profisssionais da Educação, como determina o Decreto $\mathrm{n}^{\circ} 5623$ de 22 de dezembro de 2005:

A LIBRAS deve ser inserida como disciplina Curricular obrigatória nos cursos de formação de professores para o exercício do magistério, em nível médio e superior, e nos cursos de Fonoaudiologia, de instituições de ensino, público e privados, do sistema federal de ensino e dos sistemas 
de ensino dos Estados, do Distrito Federal e dos Municípios $\left(\operatorname{art} .3^{\circ}\right)$.

A partir deste artigo foi possível promover o progresso no sentido do estabelecimento de escolas inclusivas, mas para que esse processo tenha uma continuidade seria preciso que o MEC também fornecesse capacitação continuas através de cursos e que não somente os professores tenham acesso a esse tipo de capacitação, pois os demais profissionais do sistema escolar precisam se conscientizar de como é importante conhecer a cultura do surdo e saber que geralmente ele é um aluno bilíngue e que a língua materna dele é a língua de sinais e não a língua portuguesa e que nessa língua é fundamental a expressão facial e corporal. Dessa forma a equipe toda poderia amadurecer profissionalmente.

O que não pode ser esquecido é que qualquer profissional tem a condição de realizar alguma coisa para incluir o indivíduo e é importante ressaltar que o papel da escola não se limita a transmissão de conhecimentos, mas ela também precisa se preocupar com o afeto, o calor humano e assim oferecer uma escola de qualidade onde ensinar é sinônimo de aprender, como cita Freire (2002, p. 26) "Ensinar inexiste sem aprender e vice-versa e foi aprendendo que, historicamente mulheres e homens descobriram que era possível ensinar".
Contudo o espaço escolar não está adequado a essa forma de ensinar e aprender, a escola tradicional resiste a inclusão, pois percebe sua falta de capacidade de atuar diante da complexidade, da diversidade, da variedade do que é real nos seres e nos grupos humanos. Aparentemente, nas escolas todas as crianças são bem-vindas, indiscriminadamente. Não adianta, contudo, a escola permitir o acesso e não garantir a permanência desse aluno, para que o mesmo possa prosseguir avançado em seu nível escolar.

Segundo Mantoan (2003) a inclusão é uma inovação que implica diretamente uma modernização e reestruturação, principalmente da forma como o ensino é ministrado e de como a aprendizagem é concebida e avaliada. Quando se trata do aprendizado e da avaliação do aluno surdo, percebe-se que essa reestruturação é de extrema necessidade, pois o aluno em questão, não é um ser auditivo, mas sim um ser visual e por isso ele tem necessidade de recursos do tipo que vai muito além da aula traduzida pelo intérprete, ele precisa de imagens, figuras que ilustrem a aula, de materiais que sejam táteis, pois é através desses símbolos que o aluno vai poder associar a informação traduzida em LIBRAS e assim processar o conhecimento ensinado. 
Porém até que essas aulas enriquecedoras sejam uma rotina dentro da escola a mesma precisa sofrer diversas alterações com urgência. Uma escola aberta a todos, é o grande alvo e, ao mesmo tempo, o grande problema da educação nestes novos tempos. Um dos desafios para uma nova escola de qualidade é criar espaços educativos de construção de personalidades humanas autônomas, criticas, espaços onde crianças e jovens aprendam a ser pessoas que valorizem a diferença do seu semelhante.

De certa forma essa inclusão assusta, porém ela é como muitos a apregoam, "um caminho sem volta", pois a tendência é a cada ano aumentar número de alunos portadores de necessidades especiais, incluindo, os surdos. Por mais que o movimento inclusivo "ainda seja contestado, pelo caráter ameaçador de toda e qualquer mudança, especialmente no meio educacional, convence a todos pela sua lógica e pela ética de seu posicionamento social". (MANTOAN, 2003 p.91). Esta colocação merece destaque e tempo de reflexão, pois realmente é ilógico no atual contexto histórico e social, pensar em educação sem se pensar em inclusão.

A primeira Carta Constitucional que trata sobre os direitos de acesso ao mercado de trabalho para pessoas com deficiência é a Constituição de 1988. Segundo Fonseca, o artigo $7^{\circ}$ da mesma, proíbe qualquer tipo de discriminação seja salarial ou por critérios de admissão em relação ao trabalhador portador de deficiência. Assim como também diz respeito à obrigatoriedade de reservas de postos de trabalho a portadores de deficiência nos seguintes percentuais:

Art. 93- A empresa com 100 (cem) ou mais empregados está obrigada a preencher $2 \%$ (dois por cento) a $5 \%$ (cinco por cento) dos seus cargos com beneficiários reabilitados ou pessoas portadoras de deficiência, habilitadas, na seguinte proporção":

- De até 200 empregados (...) 2\%

- De até 201 a 500 empregados (...) 3\%

- De até 501 a 1.000 empregados (...) 4\%

- De até 1001 em diante (...) 5\% (BRASIL, 1991).

Assim como as empresas têm obrigatoriedade de reservar um percentual de suas vagas para pessoas com deficiência a União também possui essa obrigação, pois a Lei $\mathrm{n}^{\circ} 8.112$, impõe que a mesma reserve, em seus concursos, até $20 \%$ das vagas a portadores de deficiências.

A Constituição de 1988 no artigo 227, também prevê um atendimento especializado para portadores de deficiência física, sensorial ou mental, bem como integrar socialmente o adolescente portador de deficiência, mediante treinamento para o trabalho e a convivência, e a facilitação do acesso aos bens e serviços coletivos.

Como se pode notar todas essas leis incluem o surdo de uma maneira implícita, 
pois o mesmo possui uma deficiência sensorial, porém existe um decreto de $n^{\circ}$ 5.626, de 22 de dezembro de 2005 que prioriza explicitamente a vaga de trabalho para pessoas surdas, como a formação de docentes para o ensino de Libras nas séries finais do ensino fundamental; a formações de docentes para o ensino de Libras na educação infantil e nos anos iniciais:

$\S 2^{\circ}$ As pessoas surdas terão prioridade nos Art. $6^{\circ}$. A formação do instrutor de Libras, em nível médio, deve ser realizada por meio de".

I - Cursos de educação profisssional

II - Cursos de formação continuada promovida por instituições de ensino superior; e

III - cursos de formação continuada promovida por instituições credenciadas por secretarias de educação.

$\S 1^{\circ} \mathrm{A}$ formação do instrutor de Libras pode ser realizada também por organizações da sociedade civil representativa da comunidade surda, desde que o certificado seja convalidado por pelo menos uma das instituições referidas nos incisos II e III $\S 2^{\circ}$ As pessoas surdas terão prioridade nos cursos de formação previstos no caput (BRASIL, 2005).

Como se pode compreender através do artigo $6^{\circ}$ acima, e das demais colocações já feitas, o Brasil contempla um conjunto de leis brilhantes que amparam de uma forma geral ou específica o surdo para sua inserção ao mercado de trabalho, seja por meio de cotas ou mesmo por preferência como no caso do Instrutor de Libras. Também já foram brevemente explanados pontos que abordam a inclusão do aluno com deficiência, primordialmente focados na Declaração de
Salamanca e outros seminários, encontros e decretos surgidos a partir desta.

Enfim, já existe toda uma formalização em relação aos direitos da pessoa surda, e dos demais portadores de deficiência; porém, é notável certa contradição epistemológica, quando se analisa, principalmente, o mercado de trabalho para pessoas que fazem parte de uma minoria na sociedade, (LODI, 2009) as quais produzem muito, consomem o mínimo e dessa forma:

Muitas pessoas portadoras de deficiência continuam vagando por este mundo sobrevivendo e sendo superexplorados, em nome de sua "eficiência" e disposição. Esses são incluídos nas políticas sociais, na empresa, na escola, mas ao mesmo tempo recebem salários inferiores em relação aos considerados superiores (LODI, et al, 2009, p. 148).

A partir desta afirmação então, é relevante perceber que especialmente $o$ mercado de trabalho para pessoas com deficiência ainda precisa ser reajustado em muitos pontos, até que possa realmente cumprir o que as leis e decretos tanto amparam e defendem. É claro que os processos evolutivos pelos quais a sociedade passa, são lentos e trabalhosos por parte de quem luta por eles. Mas, em se tratando de mercado de trabalho para o surdo, vale ressaltar que no estado de Mato Grosso do Sul na década de 80 esses trabalhadores já buscavam obter sua renda sendo vendedores ambulantes (ALBRES, 2005). 
Tal atividade não lhes assegurava uma renda estável, nem muito lucrativa. Daquele período até a atualidade se passaram exatamente três décadas. Será que as pessoas com surdez conseguiram aprimorar seu aspecto financeiro e, consequentemente, seu espaço no mercado de trabalho? Ou continuam no mesmo estilo de trabalho dos surdos da década de 80 ? Essas reflexões farão parte da discussão que procurará mostrar os percalços que o surdo enfrenta.

\section{Materiais e Métodos}

Essa pesquisa empregou como metodologia a abordagem qualitativa e utilizou-se a técnica de estudo de caso, uma vez que para Lüdke e André (1986) apud Bodgan e Biklen (1982) a pesquisa qualitativa basicamente caracteriza-se por ter o ambiente natural como sua fonte direta de dados e tem o pesquisador como seu principal instrumento. Esses autores acreditam que a pesquisa qualitativa supõe o contato direto e prolongado do pesquisador com o ambiente e a situação investigados, em que os dados são coletados e são descritos, constituindo a base de informações nesse tipo de pesquisa, sendo muito frequente a descrição de pessoas, situações. Essa tipologia de pesquisa inclui transcrição de entrevistas e depoimentos, registro dos fatos por meio de fotografias, desenhos e extratos de vários tipos de documentos.
De acordo com os mesmos autores, pesquisa qualitativa ou naturalística envolve obtenção de dados descritivos, obtidos no contato direto do pesquisador com a situação estudada, em que se enfatiza mais o processo do que o produto e se preocupa em retratar a perspectiva dos participantes.

Por isso pode se afirmar que este tipo de pesquisa precisa ter como uma das motivações a curiosidade por descobrir novos conhecimentos. Pretende-se dessa forma, utilizar a técnica de estudo de caso, descrito por Lüdke e André (1986):

Estudos de caso procuram representar os diferentes e ás vezes conflitantes pontos de vista presentes numa situação social [...]São dados vários elementos para que o leitor possa chegar às suas próprias conclusões $\mathrm{e}$ decisões, além evidentemente das conclusões do próprio investigador [...] os relatos do estudo de caso utilizam uma linguagem e uma forma mais acessível do que os outros relatórios de pesquisa (LÜDKE e ANDRÉ, 1986, p.20).

E é exatamente desse modo que essa pesquisa transcorre, visando, expor as divergências nos pontos de vista dos entrevistados com uma forma e linguagem acessíveis e, dessa maneira, propiciar ao leitor obter suas próprias conclusões. Para tanto é necessário esclarecer que esta pesquisa foi realizada em uma escola pública de médio porte que atende, em diferentes turnos, quatorze alunos surdos. 
Inicialmente foram feitas observações e indagações para se obter a caracterização da escola, com coordenadores, professores, intérpretes e alunos surdos de variados turnos e anos, para que a partir do estudo de cada entrevista realizada se obtivesse um esclarecimento ou resposta sobre em que medida a escola tem contribuído para a inserção do surdo no mercado de trabalho.

\section{Resultados e Discussão}

Foram entrevistados cinco alunos surdos que estudam em turmas diferentes. Quando questionados se gostam da escola, os alunos $\mathrm{A}, \mathrm{B}, \mathrm{C}, \mathrm{D}$, disseram que gostam, pois aprendem todo dia novos conhecimentos e alguns professores são legais e tentam ajudar. Porém, o aluno E disse que gosta mais ou menos, porque há muita bagunça na sala. Também foram questionados sobre qual disciplina mais gostam. $\mathrm{O}$ aluno A respondeu que gosta de Ciências, o aluno B gosta de Geografia e apesar de ser difícil gosta de Matemática, o aluno $\mathrm{C}$ também gosta de Geografia e Matemática e Física. Já os alunos D e E gostam de História e Química.

Segundo o discente A os professores se comunicam, tentam ser amigos conhecem um pouquinho só de LIBRAS, precisam fazer cursos, para aprender mais e para o ajudarem melhor; em contrapartida os alunos B e D afirmaram que os professores não sabem nada da LIBRAS, e se comunicam mais através do intérprete e, às vezes, eles fazem leitura labial, mas é muito difícil compreender tudo o que o professor oraliza. Concordando com os anteriores os alunos $\mathrm{C}$ e $\mathrm{E}$ disseram que os professores só se comunicam através do intérprete.

Os alunos também foram interrogados, se trabalhavam em algum lugar. O aluno A relatou que às vezes trabalha, e há algum tempo trabalhou fazendo serviços gerais em uma empresa de turismo, mas atualmente faz "bico", trabalhando como cabo eleitoral. O aluno $\mathrm{B}$ afirmou que às vezes trabalha como manicure, mas somente quando as pessoas a procuram, mas que também trabalha em sua casa limpando e fazendo comida. $\mathrm{O}$ aluno $\mathrm{C}$ informou que trabalha em um supermercado, pesando frutas e legumes. Já o aluno D disse que muito tempo atrás trabalhou em um salão de beleza, mas que seu pai não o deixou o continuar trabalhando, pois era melhor estudar.

Para o aluno E o mercado de trabalho é muito difícil porque ele já distribuiu seu currículo em várias lojas e supermercados, mas ninguém o contrata porque ele é surdo e ninguém consegue se comunicar com ele e por isso, atualmente, vende produtos de uma revista chamada Hermes. Quando indagados sobre se a escola tem ajudado em sua inserção no mercado de trabalho, o aluno A manifestou 
se da seguinte forma: a escola não ajuda muito, apesar de conhecer a cota de deficientes no mercado de trabalho, porque a escola não tem intérprete o suficiente, que dirá intérpretes para nos ajudar a traduzir informações sobre vagas de trabalho ou mesmo para nos apresentar na empresa e a nos ajudar falando sobre os nossos currículos.

Pode se constatar que o aluno surdo nota os limites que a sociedade lhe impõe, principalmente no mercado de trabalho, o qual desconhece sua língua e nem busca ter algum tipo de comunicação com os surdos. Emílio afirma a esse respeito:

Como mudar atitudes que estão enraizadas num país em que há um discurso liberal com práticas sociais bárbaras profundamente marcadas por preconceitos raciais e de classe? [...] a prática atual defende todas as crianças na escola, mas poucos se perguntam "que escola"? O discurso da inclusão não poderia estar no bojo das atividades impostoras realizadas para desativar a bomba da indagação (EMÍLIO, 2008, p.47).

A dura realidade da sociedade contemporânea foi claramente expressa pelo autor que nos permite observar que, por trás de belas filosofias estão presentes interesses muito maiores, que objetivam somente algo: não permitir que a sociedade seja pensante, indagadora e atuante, pois esta ideia pode condizer claramente com as cotas no mercado de trabalho para pessoas com necessidades especiais, tendo em vista que essas vagas existem, mas o acesso até elas é muito limitado.

Segundo o aluno $\mathrm{B}$, às vezes, $\mathrm{a}$ coordenadora procura vaga no mercado de trabalho para o surdo, mas não ajuda muito porque aqui em Ponta Porã é muito difícil trabalho para o surdo, às vezes, as pessoas não contratam o surdo porque não sabem LIBRAS. Para o aluno $\mathrm{C}$ a escola ajudou muito, pois contribuiu para sua alfabetização e aquisição de vários conhecimentos e, principalmente, através da NUESP conseguiu inseri-lo no mercado de trabalho, em um supermercado onde trabalha há mais de três anos. Contrapondo-se à afirmação anterior os alunos D e E dizem que a escola não ajuda nessa inserção; ela ensina seus conteúdos e se limita nisso.

\section{Conclusão}

Nesta pesquisa fez-se um apanhado de conceitos teóricos formulados por pesquisadores a respeito do aluno surdo, sua história de educação, as leis que visam incluílos na sociedade e dessa forma pôde-se notar que a dificuldade de comunicação que marcou a história das pessoas surdas.

Isso também é perceptível na relação professor/aluno, pois geralmente só há comunicação quando o aluno surdo tenta 
oralizar, isto é fazer leitura labial ou na presença do intérprete. Esse fato ocorre devido grande parte dos professores não conhecerem a LIBRAS, tal realidade é ainda mais difícil quando se trata do mercado de trabalho, como foi dito por alguns entrevistados. Muitos disseram que conseguir trabalho em alguma empresa é complicado pelo fato deles serem surdos, tendo em vista que apesar da LIBRAS ser o segundo idioma oficial do Brasil, a sociedade não a conhece e muitas vezes a ignora.

Entretanto, a partir desta pesquisa bibliográfica, é notável perceber que a educação para o surdo tem avançado significativamente, pois sua Língua materna e os profissionais intérpretes têm sido valorizados na atual sociedade e com isso proporcionando uma grande melhoria na qualidade de vida dos surdos. Mas apesar da contribuição da escola, é relevante ainda enfatizar que a partir dessa pesquisa pôde-se perceber que especialmente em relação ao mercado de trabalho para pessoas com deficiência a escola ainda tem muito a contribuir. Muito há para ser revisto e ajustado em muitos pontos, para que as leis e decretos que tanto amparam e defendem, inclusive os surdos, possam de fato vigorar e garantir-lhes o direito de cidadania plena.

Por isso é necessário considerar um dos pontos mais relevantes na entrevista com os alunos: o fato de se perceber que, em sua maioria, muitos buscam de alguma forma conseguir recursos financeiros por meios próprios, seja através de algum serviço informal prestado, um "bico" ou até mesmo com a venda de algum produto para inseriremse no mercado de trabalho.

Seria pretensioso afirmar que este de mercado de trabalho do aluno surdo resume- se, somente nos espaços apresentados nesta breve pesquisa, tendo em vista que o campo de pesquisa é amplo e inovador, mas acreditase que o presente estudo possa contribuir para uma reflexão no meio acadêmico e para interessados na área. Resta ainda outro ponto merecedor de atenção, que deveria ser considerado em pesquisas futuras: a questão do fim do Núcleo de Educação Especial, que segundo informações relatadas, em anos anteriores, contribuiu significativamente para a inserção do aluno surdo no mercado de trabalho. Tal Núcleo fazia reuniões com a associação comercial, dirigia-se até as empresas, juntamente com os alunos, enfim realizava um trabalho árduo em prol dessa causa; por isso é visível a lástima que os entrevistados sentem pela extinção da NUESP e é por isso que a dúvida é pertinente e instigadora: Porque tal núcleo deixou de existir por que a escola não atinge plenamente o seu papel de contribuir para a inserção do 
aluno surdo no mercado de trabalho, em Ponta Porã?

Uma possível solução poderia surgir se a Secretaria de Educação em um trabalho conjunto com a Secretaria de Assistência Social pudesse desenvolver ações semelhantes às que a NUESP realizava, tendo em vista que a escola já possui diversos encargos, que, muitas vezes, vão além de ensinar conteúdo. Por isso, formar uma parceria com a assistência social seria um modo de amenizar uma entre tantas responsabilidades assumidas pelo sistema escolar, tão já assoberbado pelas relações que se estabelecem, a partir de sua presença nas comunidades.

\section{Referências}

ALBRES, N. D. A. História da língua brasileira de sinais em Campo Grande-MS. 2005 Disponível em: < http://editora-arara-azul.com.br/pdf/artigo15.pdf> Acesso em 14 Dez. 2017.

ARANHA, M. L. A. História da Educação. 2 ed. São Paulo: Moderna.1996.

BRASIL, Lei $n^{\circ} 8213$ de 25 de julho de 1991. Dispõe sobre os Planos de Benefícios da Previdência e dá outras providências a contratação de portadores de necessidades especiais. Diário Oficial da União, s.1, p. 14809, 1991. Disponível em: $<$ http://www2.camara.leg.br/legin/fed/lei/1991/lei-8213-24-julho-1991-363650publicacaooriginal-1-pl.html>. Acesso em 14 dez. 2017.

BRASIL, Lei $\mathrm{n}^{\mathrm{o}} 8.112$ de 11 de dezembro de 1990 . Disponível em $<$ http://www.planalto.gov.br/ccivil_03/Leis/L8112cons.htm>. Acesso em 14 dez. 2017.

BRASIL, Decreto ${ }^{\circ} 5626$ de 22 de dezembro de 2005, dispõe sobre a Língua Brasileira de Sinais - LIBRAS. Diário Oficial da União, s.1, p. 28, 2005. Disponível em < http://www2.camara.leg.br/legin/fed/decret/2005/decreto-5626-22-dezembro-2005-539842norma-pe.html> Acesso em 14 dez. 2017.

BRASIL. Constituição 1988. Constituição da República Federativa do Brasil. Brasília, DF.

EMÍLIO, S. A. Grupos e inclusão escolar: sobre laços, amarras e nós- São Paulo. Paulus, 2008.

FREIRE, P. Pedagogia da Autonomia: saberes necessários à prática educativa. Rio de Janeiro: Paz e Terra, 2002.

HONORA, M.; FRIZANCO, M. L. E. Livro Ilustrado de Língua Brasileira de Sinais: desvendando a comunicação usada pelas pessoas com surdez. 1. ed. São Paulo: Ciranda Cultura, 2009.

LODI, A. C. B.; HARRISON, K. C.; \& CAMPOS, S. Letramento e surdez: Um olhar sobre as particularidades dentro do contexto educacional." Letramento e minorias. Porto Alegre: Mediação, 2002. 


\section{REALIZZAÇ:̆̊ $\odot$}

LÜDKE, M.; ANDRÉ, M. E. Pesquisa em educação: abordagens qualitativas - São Paulo: EPU, 1986.

MANTOAN, M. T. E. Inclusão escolar: O que é? Por quê? Como? 1. ed. São Paulo: Moderna, 2003.

MORAES, J. G. V. História: Geral e do Brasil: volume único - 2.ed. São Paulo: atual 2005. 